\title{
The enigmatic phenotype: Relevant signs and symptoms in schizophrenia
}

\author{
F.W.H.M. Wijers ${ }^{*},{ }^{*}$ \\ W.M.A. Verhoeven ${ }^{*},{ }^{* *}$ \\ S. Tuinier*
}

*Vincent van Gogh Institute for Psychiatry, Venray, The Netherlands

**Erasmus University Medical Centre, Department of Psychiatry, Rotterdam

\begin{abstract}
Ever since schizophrenia was conceptualized by Kraepelin and Bleuler, attempts have been made to rearrange signs and symptoms in order to achieve an useful disease concept with consequences for outcome, prognosis, treatment response and etiology. Several procedures were used to describe relevant phenotypes of the disease. In the beginning, famous psychiatrists conceptualized definitions of schizophrenia which was followed by a consensus about the operational criteria of schizophrenia. Later, more emphasis was placed on the statistical analyses of symptoms present in patients with psychotic disorders which resulted in a great variety of symptom clusters. In another approach, investigators try to deconstruct psychiatric diagnoses in search for so called endophenotypes of which covert symptoms like cognitive deficits in schizophrenia, are an example.

The value of all these endeavours ultimately depends on the external validity which means that a relationship has to be established with the etiology, treatment response and outcome. The premises of all these research efforts is, however, the idea that the pathogenic agent of schizophrenia or a subtype will be found.

In this paper an outline of the literature about the ordening of overt and covert symptoms in schizophrenia is presented. It is concluded that the different approaches are essential analogue and that research into the delineation of cognitive deficits and their treatment is at present most promising.
\end{abstract}

\section{Introduction}

Although the psychopathological picture of Kraepelins' dementia praecox with a general weakening of mental processes resulting in a defect as cornerstone, has been described more than a century ago, the diagnosis still depends on the subjective experiences of the patient, the history and course of symptoms and the observation of behaviour and is based therefore on observable symptoms. With 
respect to symptomatology, however, it has to be stressed that symptoms of schizophrenia encompasses the entire spectrum of psychopathology with a substantial interindividual variation and that virtually any combination of symptoms may be present in an individual patient. Despite the critics on schizophrenia as a disease entity (Van Praag, 1976, Kendell 1982, 1989), it is, however, generally accepted that the disorder can be identified in different cultures and nations and has a worldwide prevalence of 1 percent and that the diagnosis is rather stable over time (WHO 1973, 1979, Kendell et al. 1979, Schwartz et al. 2000). Furthermore a wide variety of outcomes can be observed in patients with similar initial symptom characteristics (Jablensky et al. 1992, Leff et al. 1992).

Although symptoms and signs are crucial for the diagnosis of schizophrenia, there is an ongoing debate since Kraepelin about how to group symptoms or to subtype this disorder with the aim of discovering the nature of schizophrenia and its outcome and prognosis (Strauss et al. 1974). The search for the ideal phenotype deals with composing 'Idealtypen', relevant subtypes, delineation of symptom clusters by means of statistical procedures, the description of underlying cognitive deficits and the identification of so called endophenotypes. The present paper reviews these different approaches and tries to answer the simple question what approach is the most relevant for outcome and prognosis.

\section{Diagnostic typing and subtyping}

Since the original description by Kraepelin of the dementia praecox with its subtypes and the longitudinal outcome as diagnostic criterion, various attempts have been made to arrange the manifold symptoms and signs of schizophrenia. In 1911 Eugen Bleuler introduced the so called 'fundamental' and 'accessory' symptoms which comprise loosening of associations, ambivalence and autism on the one hand, and hallucinations, delusions and catatonic signs on the other hand. According to Bleuler (1911) fundamental symptoms are obligatory for the diagnosis. In the fifties, Kurt Schneider $(1950,1957)$ formulated, on an entirely pragmatic base, the so called first rank symptoms of schizophrenia that were believed to have a crucial significance for the diagnosis. They included eleven symptoms such as audible thoughts, third person auditory hallucinations, interference with the thought process or delusional perception. Schneider himself, however, never referred to these symptoms as pathognomonic for schizophrenia. The emphasis on Schneider-like symptoms was reinforced by the effects of neuroleptics in alleviating them. Despite the clinical effects of these compounds, a majority of patients was still disabled due to persistent Bleulerian fundamental symptoms.

Kraepelins' original distinction of defective and productive symptoms was in the seventies revived by the positive and negative symptom distinction. This dichotomy was described in some form in most theoretical constructs before that time. According to Berrios (1985) this terminology, that stems from observations in epilepsy, was first mentioned by John Russell Reynolds in 1858 and elaborated subsequently by John Hughlings-Jackson in the eighties of the nineteenth century. The concept of Jackson (1887) is based on the doctrine of the dissolution of higher nervous functions. His theory of a hierarchy of levels of functional organisation in the nervous system implied that positive symptoms such as delusions 
and hallucinations represented release phenomena, arising when a higher cortical regulator has been lost and the activity from a lower level therefore emerged unchecked. Negative symptoms were due to 'dissolution', that is they represented a diffuse and generalised loss of higher centres.

Until the present day the positive-negative symptom polarity is used in the dissection of schizophrenia and this was given again impetus by Crow (1980a,b) who proposed to group the symptoms and signs of schizophrenia as either positive or negative, the so called type I and type II schizophrenia. According to Crow, type I is characterised by positive symptoms like delusions, hallucinations and formal thought disorder that occurs usually in the setting of an acute illness, while type II is defined by negative symptoms such as blunting of affect and poverty of speech as well as indices of structural cerebral abnormalities which generally shows a chronic course (Crow 1985). He hypothesized that these types represent two etiological distinct subtypes. Subsequent factor analytical studies suggested that these types represent the two ends of a continuum (Andreasen and Olsen 1982, Lewine et al. 1983). It should be stressed, however, that the placement of symptoms in either category is purely descriptive and rather arbitrary. In reviewing the literature, Walker and Levine (1988) concluded that only six symptoms were consistently classified as either negative or positive that are included in de widely used scales. In addition, Carpenter et al. (1988) proposed to distinguish primary from secondary negative symptoms in which the primary deficit symptoms are enduring traits that include anhedonia, flattening of affect, poverty of speech and lack of motivation. To the nondeficit negative symptoms belong psychomotor slowness, anergia and social with- drawal that depend on mood state and side effects of medication.

The ambiguity of the negative-positive dichotomy is best illustrated by symptoms like thought and speech disorder as well as catatonic features which are difficult to place in either group. The difficulties in the appreciation of motor symptoms can be inferred from the specific history of catatonia, originally recognised as a separate disease entity by Karl Ludwig Kahlbaum and later considered to be a subtype of schizophrenia or an accessory symptom in various neuropsychiatric disorders (review: Van der Heijden et al. 2005).

\section{The two-factor model}

As elegantly described by Jablensky (2001), grouping of symptoms has been done on the basis of expert clinical impression like the fundamental and accessory symptoms as described by Bleuler or the hierarchical continuum as proposed in later works by Kraepelin, and the frequency profiles of symptoms. By applying statistical procedures to discover latent variables or factors, Liddle (1987a) found a three factor structure of symptomatology instead of the previously described positive and negative dimensions. Symptoms, assessed in a relatively small sample of stable patients with schizophrenia, segregated into three syndromes: psychomotor poverty, disorganisation and reality distortion, of which the first two were associated with social and occupational impairment. Later, Peralta et al. (1994) proposed on the basis of a larger patient group a four syndrome model including positive, negative, disorganisation and relational dimensions. It should be stressed, however, that the results of this kind of studies are highly dependent on the input, in that the number of factors 
required to explain the variance is greater when a wider range of symptoms is used. Furthermore, the results are influenced by the patient population investigated, sample size, age, duration, course and outcome of illness, response to treatment and the applied diagnostic criteria. In addition, the stability of factors over time is still questionable (Arndt et al. 1995, Eaton et al. 1995, McGuffin \& Farmer 2001).

In the first decades of the past century, several subtypes of schizophrenia were described that ultimately resulted in eight categories in the ICD-9: simple, hebephrenic, catatonic, paranoid, schizoaffective, latent and residual and acute, whereas the DSM-III recognised five categories: disorganised, catatonic, paranoid, undifferentiated and residual. Others emphasized that this subdivision is based on the predominant clinical picture at evaluation (Kendell 1987, McGlashan \& Fenton 1991). Many other subgroups based on clinical pictures have been proposed of which those of Kleist and Leonhard are examples of clinical ideographic classifications (Leonhard 1995, review: Van der Heijden et al. 2002). These rather detailed subdivisions, however, are flawed by the observation that many patients do not lie within any particular subgroup and that changes to another subgroup frequently occur during the course of the illness (Fenton \& McGlashan 1991)

Starting in the sixties, several studies have been performed in order to regroup psychotic symptoms (Wing 1961, 1978, WHO 1973). This type of research was promoted by the availability of rating scales like the Scale for Assessment of Negative Symptoms (SANS) and the Scale for Assessment of Positive Symptoms (SAPS) (Andreasen 1983, 1984), as well as the introduction of modern statistical programs. These scales were developed on the assumption that there are two major syndromes that account for schizophrenic phenomena (Klimidis et al. 1993). In the early eighties Crow as well as Andreasen and co-workers published their data on the positive-negative symptom polarity in schizophrenia. Andreasen and Olsen (1982) confirmed the polarity between positive and negative symptoms and described a mixed group comprising symptoms that either do not meet the criteria for positive or negative symptoms or are in agreement with the criteria for both. These three groups differed on a number of variables such as premorbid adjustment, the overall functioning, impaired cognitive function and indications of cerebral structural abnormalities. In a review of the literature, Walker and Levine (1988) conclude that, in accordance with the original concept from 1858 by Reynolds, the two symptom dimensions in schizophrenia are relatively independent and that the negative symptoms are associated with premorbid dysfunction and cognitive impairments. In an attempt to amend the homogeneity of negative symptoms, Carpenter et al. (1988) made a distinction between the primary or enduring negative symptoms termed deficit symptoms and the more transient non-deficit negative symptoms secondary to other factors like drug effect, dysphoric mood and absence of social stimulation.

\section{Factor analytical studies based on the two-syndrome model}

As mentioned above a three dimension model of schizophrenia was originally described by Liddle (1987a,b). The symptoms obtained in a sample of 40 chronic schizophrenic patients selected for persistence of symptoms and a duration of illness of at least 3 years without an exacerbation of symptoms or changes in drug treatment during the previous 6 months. The symp- 
toms segregated into three syndromes 'psychomotor poverty' (poverty of speech, lack of spontaneous movement and various aspects of blunting affect), 'disorganisation' (inappropriate affect, poverty of content of speech and disturbances of the form of thought) and 'reality distortion' (particular types of delusions and hallucinations). The latter did not correlate with cognitive or neurological dysfunction. In a subsequent study, Liddle and Barnes (1990) replicated these results and found that the syndromes 'psychomotor poverty' and 'disorganisation' are linked to neuropsychological deficits such as conceptual reasoning, longterm memory, concentration and new learning. In contrast to the classical subtyping that attempts to identify discrete types of illness, it was demonstrated that the three syndromes may coexist in the same patient. Similar observations in various samples of schizophrenic patients were reported by Arndt et al. (1991) and in a later study by Andreasen et al. (1995). A comparable three component model was found in a sample of patients with chronic schizophrenia (Brown $\&$ White 1992) and in a random sample of schizophrenic patients with at least six months of symptoms (Johnstone \& Frith 1996). In the study with chronic patients, only the 'psychomotor poverty' dimension was associated with neuropsychological impairments. In this large group of unselected patients, cognitive deficits appeared to be unrelated to the dimension of 'reality distortion'. In subsequent studies by Van der Does and co-workers in patients with recent-onset schizophrenia, also three clusters of symptoms could be established. As a result of the use of different symptom scales, a fourth factor emerged: 'depression'. Only 'disorganisation' was correlated with cognitive performance deficits (Van der Does et al. 1993 a,b, 1995, 1996). The above mentioned studies that are reviewed by Buchanan and
Carpenter (1994) show that the positive-negative symptom dichotomy is too restricted and should be expanded to at least a threedimensional model. This was replicated in some later studies (Löffler \& Häfner 1999, Peralta et al. 2001, John et al. 2003). It should be stressed, however, that studies that found three syndromes did not included the entire range of symptoms in schizophrenic patients such as the common motor features (Peralta \& Cuesta 2001).

As already stipulated in 1994 by Liddle, two additional syndromes, depression and psychomotor excitation, can be identified if affective items and features of overarousal are included too (Liddle et al. 1994). Furthermore, it has been demonstrated that the three psychopathological domains are not unique for schizophrenia and can also be found in other diagnostic categories (Ratakonda et al. 1998).

The generalizability of the results of the studies that demonstrated two or three dimensions is, however, limited since they included samples composed of patients with DSM-core schizophrenia and the analyses are mostly based on SAPS and SANS scores. The majority of the models as described in the seventies and eighties have been obtained by exploratory factor analysis of these two scales in patients who met a categorical diagnosis of schizophrenia (review: Peralta et al. 1994). As the SAPS and the SANS were designed to measure negative and positive symptoms it is not surprising that factor analysis of their ratings results in negative and positive dimensions. The outcome reflects the underlying concepts especially if other symptoms that form an integral part of schizophrenia such as affective and motor symptoms are excluded.

In later years, factor analytical studies were performed that use a great variety of 
scoring instruments. As reviewed by Von Knorring and Lindström (1995) and confirmed by other investigators (Lykouras et al. 2000), principal component analysis of the Positive and Negative Syndrome Scale (PANSS, Kay et al. 1987) revealed a five factor model comprising: negative, excitement, depression, positive and cognitive impairment. A later study demonstrated four factors: negative symptoms, disorganized thought, hostility/excitement and delusions/hallucinations (Hwu et al. 2002). A four or five factor structure was also found with the Comprehensive Psychopathological Rating Scale (CPRS, Asberg et al. 1978) that resembled the dimensions of the scale itself (Arora et al. 1997, Salokangas 1997, Van Os et al. 1999). With the AMDP-system (Scharfetter 1983), even a 10-dimensional model was found (Cuesta \& Peralta 2001, Cuesta et al. 2003). With other scales a 4 to 5 factor structure has been described (Kitamura et al. 1995, McGorry et al. 1998).

It should be kept in mind that the decision as to whether the dimensions found are valid, must be based on external criteria such as e.g. outcome and treatment response as well as pathophysiological and etiological parameters. As pointed out by Lieberman (1995), symptom clusters should be considered as purely descriptive and do therefore not differ essentially from the traditional qualitative subtypes of schizophrenia. The great discrepancies in the reports on the number of dimensions underlying psychosis can be explained by the inclusion of categorical defined schizophrenic patients, the use of global rating of the SAPS/SANS or the PANSS only and the instrument dependency of the results (Cuesta \& Peralta 2001). In addition, Stuart et al. (1999) demonstrated that studies that indicated low numbers of syndromes suffered from severe limitations such as exclusion of many items from the analyses, samples restricted to chronic schizophrenia and a poor fit of the symptom model to the data.

\section{Operational criteria and polydiagnostic approach}

Since the early sixties of the past century an epistemological discussion about the scientific quality of psychiatry is ongoing (Hempel 1961, Kendell 1975a, Van Praag 1978). The specificity of so called schizophrenic symptoms has also been challenged by Pope and Lipinski (1978). This debate is mainly focussed on the concept of schizophrenia with its controversial definitions and its problems of taxonomy and has resulted in a series of explicit operational criteria for the diagnosis (Brockington et al. 1978, Stephans et al. 1982). All these systems, however, are based on a more or less accurate recording of signs and symptoms and should therefore still be regarded as a set of clearly stated working hypotheses. It is therefore difficult to determine whether one definition of schizophrenia has a greater validity than any other. Different operational definitions may have a differential utility in terms of external validity. This is illustrated by the results of the twin studies from the Maudsley Hospital which showed that some definitions, including DSM schizophrenia, defined a syndrome of high heritability while a definition based on Schneider's first rank symptoms defined a syndrome of zero heritability (McGuffin et al. 1984, Farmer et al. 1987). As shown by Brockington et al. (1978) who applied 10 definitions of schizophrenia to two samples of psychotic patients, only four definitions emerged as relatively effective predictors of social and clinical outcome, whereas Schneider's symptoms proved weak in all areas of prediction. In a large long-term study using 9 
different sets of criteria it was demonstrated that quite different groups of schizophrenic patients were obtained by applying differing diagnostic criteria. The correlation with longterm follow-up status in these differently defined patients with schizophrenia appeared to be related to the number of variables having prognostic significance that are used in making the diagnosis (Stephans et al. 1982).

Given the low diagnostic concordance between several definitions of functional psychoses and the absence of an adequate criterion validity, none of the diagnostic systems can claim superiority over an other (McGorry et al. 1992, Van der Heijden et al. 2004). It was therefore advocated to use a polydiagnostic approach that includes mixed and atypical psychotic disorders as well, assuming that psychoses form a continuum without clear boundaries between syndromes. Based on these premises, McGuffin et al. (1991) developed an operational criteria checklist for recording and scoring information from a variety of sources while maintaining sufficient flexibility to apply multiple types of operational criteria, the so called OPerational CRITeria (OPCRIT) diagnostic system. This checklist is a 90-item schedule giving basic demographic information, indices of disease scores and severity, and ratings of psychotic and affective symptoms which generates reliable diagnoses according to 12 operational diagnostic systems (Craddock et al. 1996, Azevedo et al. 1999, McGuffin \& Farmer 2001). The OPCRIT can be considered as the European response to the array of phenomena in the psychoses. In the United States a parallel development was started by Andreasen in 1985 that resulted in the construction of the Comprehensive Assessment of Symptoms and History, the CASH (Andreasen, 1985; Andreasen et al., 1992). The OPCRIT is in use as the standard to make diagnoses in genetic studies in schizophrenia.

\section{Factor analytical studies with the OPCRIT}

Cardno and co-workers (1996) were the first to compare data from factor analysis of schizophrenic symptoms by means of 21 psychosis items of the OPCRIT with those of previous factor analytical studies in DSM-schizophrenia. They found that a five factor model with the predominant symptom types: paranoid, negative, disorganisation, first rank delusions and first rank hallucinations, accounted best for the data, instead of the three factor solution of positive, negative and disorganisation.

Since then a few studies using the OPCRIT have been performed to identify symptom dimensions in patient populations with psychotic disorders (Table I). By using 20 items, Van Os et al. (1996) demonstrated seven underlying structures that accounted for $63 \%$ of the variance. The first includes bizarre behaviour, catatonia, inappropriate affect and difficult rapport (inappropriate-catatonia), the second delusions of passivity, bizarre delusions, thought interference and hallucinations (delusions-hallucinations), the third mania, grandiose delusions and relationship psychotic/affective symptoms (mania), the fourth insidious onset, blunting of affect and age of onset (insidious-blunting), the fifth depression and depressive delusions (depression) and the last two lack of insight and paranoid delusions respectively. In a study including 66 patients with schizophrenia, Cardno et al. (1997) found even eight factors that are to some extent quite different from the seven described by Van Os et al. (1996). In a mixed sample of psychotic and depressed patients, Serretti et al. (1996) identified on the basis of 
38 items three psychosis-factors (excitement, disorganization and delusion) and one affective factor (depression). In an extension study using 46 items, Serretti et al. (2001) confirmed their previous four factor model. Comparable results were obtained by McIntosh et al. (2001). In a twin study aimed to elucidate useful phenotypes for genetic studies, Cardno et al. (2001) described six psychotic dimensions, comprising a disorganised, a negative and 4 positive factors. In a very heterogeneous patient group, schizophrenic psychoses could be characterized by four dimensions: positive, negative, dysphoria and mania (Rosenman et al. 2003). In a group of patients with functional psychoses, Serretti and Olgiati (2004) performed a factor analysis on 29 items and found five factors: mania, positive, disorganization, depression and negative. In a subsequent analysis, Serretti and co-workers (2004) confirmed the presence of a depression dimension in schizophrenia. Finally, Matsuura et al. (2004) described a four structure model in schizophrenic patients.

Although the OPCRIT is more comprehensive with respect to the included items, its value in research on functional psychoses is still dependent on factors that determine the external validity. Furthermore, the usefulness of this method is limited. Different syndromes may exist in the same patient, correlations between symptom factors have demonstrated to be sometimes high and subtypes or dimensions have a modest stability over time.

\section{Neurocognitive functions as covert symptoms}

Apart from the symptomatological domains that can be ascertained by standardized clinical instruments like the PANSS and the OPCRIT, it is widely accepted that cognitive deficits such as inattention, memory and executive function, are core features of schizophrenia and can be considered as covert symptoms. In general, the results of cognitive tests indicate that this disorder is characterised by a broadly based cognitive impairment. Although the pattern of these deficits is highly variable, there is some empirical evidence that cognitive performance tends to be related to negative symptoms (Bilder et al. 1985, Rund 1998, Aleman et al. 1999, Bozikas et al. 2004). It should be stressed, however, that any selective deficits in specific functions are relative and exist against the background of general dysfunction (Heinrichs et al. 1998) and that the relationship between cognitive impairments and symptom dimensions in general is weak (Mohamed et al. 1999, Bilder et al. 2000, O'Leary et al. 2000, Nieuwenstein et al. 2001, Donohoe \& Robertson 2003).

As reviewed by Green (1996), certain neurocognitive deficits like vigilance, verbal memory and executive functioning seem more predictive for functional outcome than are psychotic symptoms. In a subsequent meta-analysis Green and co-workers (2000) confirmed that these aspects of neurocognition are involved in the functional outcome indeed and that composite measures explain 20 to $60 \%$ of the variance. They suggested that measures such as social cognition and learning potential may be more fundamental for the neurocognitive assessment of patients with schizophrenia. Other investigators have focussed on attention impairment as an important predictor of outcome (review: Michie et al. 2000). It has to be emphasized again that correlations between cognitive performance and severity of psychotic symptoms are generally absent and that the correlation between negative symptoms and cognitive performance is not very large 
Table I

Factor analytical studies with the OPCRIT in patients with psychotic disorders

\begin{tabular}{|c|c|c|c|c|c|c|c|}
\hline Author & $\begin{array}{l}\text { Number } \\
\text { of patients }\end{array}$ & $\begin{array}{l}\text { Number } \\
\text { of items }\end{array}$ & $\begin{array}{c}\text { Mean } \\
\text { age }\end{array}$ & $\begin{array}{l}\text { Age } \\
\text { of onset }\end{array}$ & Diagnosis & $\begin{array}{c}\text { Inclusion } \\
\text { criteria }\end{array}$ & Dimensions \\
\hline $\begin{array}{l}\text { Cardno } \\
\text { et al. } 1996\end{array}$ & 102 & 21 & 45.1 & 24.7 & Schizophrenia & DSM-III-R & $\begin{array}{l}\text { 1) paranoid } \\
\text { 2) negative } \\
\text { 3) disorganisation } \\
\text { 4) first-rank delusions } \\
\text { 5) first rank hallucinations }\end{array}$ \\
\hline $\begin{array}{l}\text { Van Os } \\
\text { et al. } 1996\end{array}$ & 191 & 20 & 26.4 & 24.4 & $\begin{array}{l}\text { Functional } \\
\text { Psychoses }\end{array}$ & $\begin{array}{l}\text { Psychotic } \\
\text { disorder }\end{array}$ & $\begin{array}{l}\text { 1) inappropriate-catatonia } \\
\text { 2) delusions-hallucinations } \\
\text { 3) mania } \\
\text { 4) insidious-blunting } \\
\text { 5) depression } \\
\text { 6) lack of insight } \\
\text { 7) paranoid delusions }\end{array}$ \\
\hline $\begin{array}{l}\text { Serretti } \\
\text { et al.1996 }\end{array}$ & 1004 & 38 & 42.1 & 29.4 & $\begin{array}{l}\text { Major } \\
\text { psychoses }\end{array}$ & $\begin{array}{l}\text { Psychotic } \\
\text { disorder }\end{array}$ & $\begin{array}{l}\text { 1) excitement } \\
\text { 2) depression } \\
\text { 3) disorganisation } \\
\text { 4) delusion }\end{array}$ \\
\hline $\begin{array}{l}\text { Cardno } \\
\text { et al. } 1997\end{array}$ & 66 & 19 & 36.6 & 30.3 & Schizophrenia & $\begin{array}{l}\text { Research } \\
\text { Diagnostic } \\
\text { Criteria }\end{array}$ & $\begin{array}{l}\text { 1) positive formal thought disorder } \\
\text { 2) first rank delusions } \\
\text { 3) first rank hallucination } \\
\text { 4) inappropriate affect and } \\
\text { bizarre behaviour } \\
\text { 5) negative symptoms } \\
\text { 6) grandiose/bizarre } \\
\text { delusions } \\
\text { 7) delusions of influence } \\
\text { 8) other hallucinations }\end{array}$ \\
\hline $\begin{array}{l}\text { Serretti } \\
\text { et al. } 2001\end{array}$ & 2241 & 46 & 41.7 & 28.5 & $\begin{array}{l}\text { Major } \\
\text { psychoses }\end{array}$ & $\begin{array}{l}\text { Psychotic } \\
\text { disorder }\end{array}$ & $\begin{array}{l}\text { 1) excitement } \\
\text { 2) depression } \\
\text { 3) disorganisation } \\
\text { 4) delusion }\end{array}$ \\
\hline $\begin{array}{l}\text { Rosenman } \\
\text { et al. } 2003\end{array}$ & 980 & 64 & 39.3 & $\begin{array}{c}39.3 \\
\text { (mean age) }\end{array}$ & $\begin{array}{l}\text { Psychotic } \\
\text { disorder }\end{array}$ & $\begin{array}{l}\text { Psychotic } \\
\text { disorder }\end{array}$ & $\begin{array}{l}\text { 1) positive } \\
\text { 2) negative } \\
\text { 3) dysphoria } \\
\text { 4) mania }\end{array}$ \\
\hline $\begin{array}{l}\text { Serretti and } \\
\text { Olgiati } 2004\end{array}$ & 1294 & 29 & 41.7 & 28.5 & $\begin{array}{l}\text { Schizophrenia } \\
\text { Bipolar disorder } \\
\text { Delusional } \\
\text { disorder }\end{array}$ & DSM-IV & $\begin{array}{l}\text { 1) mania } \\
\text { 2) positive } \\
\text { 3) disorganization } \\
\text { 4) depression } \\
\text { 5) negative }\end{array}$ \\
\hline $\begin{array}{l}\text { Matsuura } \\
\text { et al. } 2004\end{array}$ & 116 & 60 & 39.2 & $29.9 / 24.6$ & $\begin{array}{l}\text { Epileptic } \\
\text { psychoses/ } \\
\text { Schizophrenia } \\
\text { spectrum disorde }\end{array}$ & $\begin{array}{l}\text { Not } \\
\text { mentioned }\end{array}$ & $\begin{array}{l}\text { 1) mania } \\
\text { 2) negative } \\
\text { 3) depressive } \\
\text { 4) vegetative } \\
\text { 5) positive }\end{array}$ \\
\hline
\end{tabular}


(Goldberg et al. 1993, Mohamed et al. 1999, Bilder et al. 2000, Green et al. 2004a).

It is as yet unclear whether the replacement of symptom profiles by cognitive deficits or other so called endophenotypes will be of significance for insight in the etiology of functional psychoses (Gottesman \& Gould 2003, Zobel \& Maier 2004). Delineation of phenotypes on the (sub)symptomatological level with the ultimate aim to distinguish etiological or pathogenetic factors is severely hampered by the phenotypical variability that is the rule even when etiology is known (Goldberg \& Weinberger 1995, Baron 2001).

\section{Diagnoses and syndromes as predictors of course and outcome}

The usefulness of the delineation of diagnoses, syndromes and dimensions highly depends on external validation which implies that, apart from consensus about operationally defined categories and their reliability, a relationship should be present with etiology, pathophysiology, treatment response or outcome. With respect to the operational definitions, it is well established that they include different patient groups and show a considerable variation in predicting functional outcome (Brockington et al. 1978, Kendell et al. 1979, McGorry et al. 1992). As can be inferred from the prospective WHO studies, the initial symptom characteristics are associated with a very heterogeneous outcome and variables like insidious onset, premorbid functioning, age at onset and gender are consistently related to poor prognosis albeit that their relevance for later social functioning remains uncertain. Furthermore, the future disability depends on the level of function- ing in the early course of the illness and much less on sociodemographic or illness characteristics (Jablensky et al. 1992, Wiersma et al. 2000, Häfner 2000).

Factor analytic studies have yielded a modest association with course and outcome of illness. Although the relationship between symptoms and outcome has been extensively studied, the results are still inconclusive. There are some indications that negative symptoms moderately predict poor quality of life in the early course of schizophrenia (Wieselgren et al. 1996, Ho et al. 1998). The few results obtained with the OPCRIT indicate that several symptom dimensions correlate with outcome measures, albeit that the percentage explained variance is rather low (Van Os et al. 1996, Rosenman et al. 2003).

The results of these symptom-based studies are confounded by several factors like the natural course of the disease, treatment regimen, compliance, substance abuse as well as the availability and quality of healthcare services. Whether the duration of the untreated symptomatic period is independently connected with treatment response and prognosis is still a matter of debate (Verdoux et al. 2001, Norman \& Malla 2001, Fuchs \& Steinert 2004).

Deficits in cognitive and social capacities in children and adolescents have been shown to be associated with the later development of schizophrenia (Olin et al. 1998, Yung et al. 1998, Kremen et al. 1998, Davidson et al. 1999). Although cognitive impairments are a core feature of schizophrenia and of considerable significance for community outcome, it should be stressed that a host of factors apart from cognition such as psychosocial rehabilitation and educational/vocational opportunities are modifying these associations (Ragland 2003, Green et al. 2004a). 
Despite the awareness that psychotic symptoms do not predict social and functional outcome measures, all antipsychotics are targeted at the reduction of positive symptoms as measured with rating scales. So far there is no convincing evidence that either classic or so called atypical antipsychotics are effective in the improvement of negative or cognitive symptoms (Stip 2002, Awad \& Voruganti 2004, Mishara and Goldberg 2004, Verhoeven et al. 2005). This observation has stimulated the NIMH to start the so called Measurement And Treatment Research to Improve Cognition in Schizophrenia (MATRICS) initiative aimed at the development of new compounds for the cognitive deficits of schizophrenia (Green et al. 2004b).

\section{In conclusion}

The rearrangement of symptoms and types of patients has been the leitmotiv ever since schizophrenia was conceived as a disease. Both Kraepelin and Bleuler considered the accompanying negative symptoms as crucial for the diagnosis of schizophrenia that was confirmed by a poor outcome. The recognition of schizophrenia as an imprecise concept that frequently resulted in disagreements, has led to the development of a variety of operational definitions of the disorder. In the seventies of the past century at least 10 sets of diagnostic criteria were prevalent, a situation characterised by Brockington and co-workers (1978) as "a replacement of inarticulate confusion in the diagnosis of schizophrenia by a babble of precise but differing formulations of the same concept". The debate on the diagnoses was virtually finished by the development of the ICD and DSM criteria, while at the same time others advocated a polydiagnostic or flexible diagnostic approach (Carpenter et al. 1973, Kendell 1975b). Although the categorical taxonomies identify several subtypes of schizophrenia, other approaches to distinguish psychopathological syndromes have been pursued. In 1963 Lorr et al. recognised in the first quantitative study that the symptoms of psychotic disorders could be grouped into ten major syndromes of which seven were manifestations of schizophrenia. About 25 years later Liddle (1987a) proposed a three syndrome model of chronic schizophrenia that was subsequently widely accepted for schizophrenia in general. Most of the studies that found three factors used for analysis the global ratings of the SANS/SAPS. This method, however, leads to an artificial outcome since the analysis of individual items of these scales demonstrate the existence of at least 11 syndromes (Stuart et al. 1999). With other symptom checklists like the OPCRIT, 4 to 8 dimensions have been described of which the number depends on the statistical procedures. Covert symptoms like cognitive deficits are most probably more informative than overt psychotic symptoms since they are consistently related to outcome measures (Milev et al. 2005). Symptom clusters and subtypes of schizophrenia should be considered purely descriptive until their relationship to other lines of evidence such as response to treatment, course of illness, etiology and pathophysiology can be demonstrated.

These endeavours are essentially similar and can be defined as an attempt to discover relevant phenotypes on the basis of phenomenology, which for the time being will remain the cornerstone of the diagnosis and research methods of schizophrenia. Recently, Kendler (2005) stated: 'Our strongly held desires to find the explanation for individual 
psychiatric disorders are misplaced and counterproductive' and advocated explanatory pluralism as a research attitude.

\section{References}

Aleman A, Hijman R, De Haan EHF, Kahn RS. Memory impairment in schizophrenia: a meta-analysis. Am J Psychiatry 1999; 156: 1358-1366.

Andreasen NG, Olsen S. Negative versus positive schizophrenia. Definition and validation. Arch Gen Psychiatry 1982; 39: 789-794.

Andreasen NG. The scale for the Assessment of Negative Symptoms (SANS). Iowa City: University of Iowa; 1983.

Andreasen NG. The scale for the Assessment of Positive Symptoms (SAPS). Iowa City: University of Iowa; 1984.

Andreasen NG. Comprehensive Assessment of Symptoms and History (CASH). Iowa City: University of Iowa; 1985.

Andreasen NG, Flaum M, Arndt S. The Comprehensive Assessment of Symptoms and History (CASH). An instrument for assessing diagnosis and psychopathology. Arch Gen Psychiatry 1992; 49: 615-623.

Andreasen NG, Arndt S, Alliger RJ, Miller D, Flaum M. Symptoms of schizophrenia. Arch Gen Psychiatry 1995; 52: 341-351.

Arndt S, Alliger RJ, Andreasen NG. The distinction of positive and negative symptoms. The failure of a twodimensional model. Br J Psychiatry 1991; 158: 317-322.

Arndt S, Andreasen NG, Flaum M, Miller D, Nopoulos PA. Longitudinal study of symptom dimensions in schizophrenia. Arch Gen Psychiatry 1995; 52: 352-360.

Arora A, Avasthi A, Kulhara P. Subsyndromes of chronic schizophrenia: A phenomenological study. Acta Psychiatr Scand 1997; 96: 225-229.

Åsberg M, Montgomery SA, Perris C, Schalling D, Sedvall GA. Comprehensive Psychopathological Rating Scale. Acta Psychiatr Scand 1978; 271 (suppl): S5-S28.

Awad AG, Voruganti LNP. New antipsychotics, compliance, quality of life, and subjective tolerability. Are patients better off? Can J Psychiatry 2004; 49: 297-302.

Azevedo MH, Soares MJ, Coelho I, Dourado A, Valente J, Macebo A, et al. Using consensus OPCRIT diagnoses. An efficient procedure for best-estimate lifetime diagnoses. Br J Psychiatry 1999; 175: 154-157.
Baron M. Genetics of schizophrenia and the new millennium: Progress and pitfalls. Am J Genet 2001; 68: 299-312.

Berrios GE. Positive and negative symptoms and Jackson. Arch Gen Psychiatry 1985; 42: 95-97.

Bilder RM, Mukherjee S, Rieder RO, Pandurangi AK. Symptomatic and neuropsychological components of defect states. Schizophr Bull 1985; 11: 409-417.

Bilder RM, Goldman RS, Robinson D, Reiter G, Bell L, Bates JA, Papadopulos E, et al. Neuropsychology of firstepisode schizophrenia: Initial characterization and clinical correlates. Am J Psychiatry 2000; 157: 549-559.

Bleuler E. Dementia Praecox. In: Aschaffenburg G, editor. Handbuch der Psychiatrie. Leipzig und Wien: Franz Deuticke; 1911.

Bozikas VP, Kosmidis MH, Kioperlidou K, Karavatos A. Relationship between psychopathology and cognitive functioning in schizophrenia. Compr Psychiatry 2004; 45: 392-400.

Brockington IF, Kendell RE, Leff JP. Definitions of schizophrenia: concordance and prediction of outcome. Psychol Med 1978; 8: 387-398.

Brown KW, White T. Syndromes of chronic schizophrenia and some clinical correlates. Br J Psychiatry 1992; 161: 317-322.

Buchanan RW, Carpenter WT. Domains of psychopathology. An approach to the reduction of heterogeneity in schizophrenia. J Nerv Ment Dis 1994; 182: 193-204.

Cardno AG, Jones LA, Murphy KC, Asherson P, Scott LC, Williams J, Owen MJ et al. Factor analysis of schizophrenic symptoms using the OPCRIT checklist. Schizophr Res 1996; 22: 233-239.

Cardno AG, Holmans PA, Harvey I, Williams MB, Owen MJ, Mcguffin P. Factor-derived subsyndromes of schizophrenia and familial morbid risks. Schizophr Res 1997; 23: 231-238.

Cardno AG, Sham PC, Murray RM, Mcguffin P. Twin study of symptom dimensions in psychoses. Br J Psychiatry 2001; 179: 39-45.

Carpenter WT, Strauss JS, Bartko JJ. Flexible system for the diagnosis of schizophrenia: report from the WHO international pilot study of schizophrenia. Science 1973; 182: $1275-1278$.

Carpenter WT, Heinrichs DW, Wagman AMI. Deficit en non-deficit forms of schizophrenia: The concept. Am J Psychiatry 1988; 145: 578-583.

Craddock N, Asherson P, Owen MJ, Williams J, Mcguffin P, Farmer AE. Concurrent validity of the Opcrit Diagnostic System Comparison of OPCRIT diagnoses with consensus best-estimate lifetime diagnoses. Br J Psychiatry 1996, 169: 58-63. 
Crow TJ. Molecular pathology of schizophrenia: more than one disease process? Br Med J 1980a; 12: 66-68.

Crow TJ. Positive and negative schizophrenic symptoms and the role of dopamine. Brit J Psychiat 1980b; 137: 379-386.

Crow TJ. The two-syndrome concept: Origins and current status. Schizophr Bull 1985; 11: 471-485.

Cuesta MJ, Peralta V. Integrating psychopathological dimensions in functional psychoses: A hierarchical approach. Schizophr Res 2001; 52: 215-229.

Cuesta MJ, Peralta V, Gil P, Artamendi M. Psychopathological dimensions in first-episode psychoses. Trom the trunk to the branches and leaves. Eur Arch Psychiatry Clin Neurosci 2003; 253: 73-79.

Davidson M, Reichenberg A, Rabinowitz J, Weiser M, Kaplan Z, Mark M. Behavioral and intellectual markers for schizophrenia in apparently healthy male adolescents. Am J Psychiatry 1999; 156: 1328-1335.

Donohoe G, Robertson IH. Can specific deficits in executive functioning explain the negative symptoms of schizophrenia? A review. Neurocase 2003; 9: 97-108.

Eaton WW, Thara R, Federman B, Melton B, Liang K. Structure and course of positive and negative symptoms in schizophrenia. Arch Gen Psychiatry 1995; 52: 127-134.

Farmer AE, Mcguffin P, Gottesman II. Twin concordance for DSM-III schizophrenia. Scrutinizing the validity of the definition. Arch Gen Psychiatry 1987; 44: 634-641.

Fenton WS, Mcglashan TH. Natural history of schizophrenia subtypes. Longitudinal study of paranoid, hebephrenic and undifferentiated schizophrenia. Arch Gen Psychiatry 1991; 48: 969-977.

Fuchs J, Steinert T. Dauer der unbehandelten Psychose (DUP): ein brauchbarer Prädiktor für den Krankheitsverlauf? Fortschr Neurol Psychiat 2004; 72: 79-87.

Goldberg TE, Gold JM, Greenberg R, Griffin S, Schulz $\mathrm{SC}$, Pickar D et al. Contrasts between patients with affective disorders and patients with schizophrenia on a neuropsychological test battery. Am J Psychiatry 1993; 150: 1355-1362.

Goldberg TE, Weinberger DR. A case against subtyping in schizophrenia. Schizophr Res 1995; 17: 147-152.

Gottesman II, Gould TD. The endophenotype concept in psychiatry: Etymology and strategic intentions. Am J Psychiatry 2003; 160: 636-645.

Green MF. What are the functional consequences of neurocognitive deficits in schizophrenia? Am J Psychiatry 1996; 153: 321-330.

Green MF, Kern RS, Braff DL, Mintz J. Neurocognitive deficits and functional outcome in schizophrenia: Are we measuring the "right stuff"? Schizophr Bull 2000; 26: 119136.

Green MF, Kern RS, Heaton RK. Longitudinal studies of cognition and functional outcome in schizophrenia: Implications for MATRICS. Schizophr Res 2004; 72: 41-51.

Green MF, Nuechterlein KH, Gold JM, Barch DM, Cohen J, Essock S et al. Approaching a consensus cognitive battery for clinical trials in schizophrenia: The NIMHMATRICS conference to select cognitive domains and test criteria. Biol Psychiatry 2004; 56: 301-307.

Häfner H. Onset and early course as determinants of the further course of schizophrenia. Acta Psychiatr Scand 2000; 102: 44-48.

Heinrichs RW, Zakzanis K. Neurocognitive deficit in schizophrenia: A quantitative review of the evidence. $\mathrm{Neu}$ ropsychology 1998; 12: 426-445.

Hempel CG. Introduction to problems of taxonomy. In: Zubin J. editor: Field studies in the mental disorders. New York: Grune \& Stratton; 1961.

Ho BC, Nopoulos P, Flaum M, Arndt S, Andreasen NC. Two-year outcome in first episode schizophrenia: predictive value of symptoms for quality of life. Am J Psychiatry 1988; 155: 1196-1201.

Hwu HG, Chen CH, Hwang TJ, Liu CM, Cheng JJ, Lin SK et al. Symptom patterns and subgrouping of schizophrenic patients: Significance of negative symptoms assessed on admission. Schizophr Res 2002; 56: 105-119.

Jablensky A, Sartorius N, Ernberg G, Anker M, Korten A, Cooper JE et al. Schizophrenia: Manifestations, incidence and course in different cultures. A World Health Organization ten-country study. Psychol Med Monogr1992; 20 (Suppl): S1-S97.

Jablensky A. Symptoms of schizophrenia. In: Henn F, Sartorius N, Helmchen H, Lauter H, editors: Contempory psychiatry. New York: Springer-Verlag ; 2001. p 6-36.

Jackson JH. Remarks on evolution and dissolution of the nervous system. J Mental Science 1887; 33: 25-48.

John JP, Khanna S, Thennarasu K, Reddy S. Exploration of dimensions of psychopathology in neurolepticnaïve patients with recent-onset schizophrenia/ schizophreniform disorder. Psychiatry Res 2003; 121: 11-20.

Johnstone EC, Frith CD. Validation of three dimensions of schizophrenic symptoms in a large unselected sample of patients. Psychol Med 1996; 26: 669-679.

Kay SR, Fiszbein A, Opler LA. The positive and negative syndrome scale (PANSS) for schizophrenia. Schizophrenia Bull 1987; 13: 261-276.

Kendell RE. Schizophrenia: The remedy for diagnostic confusion. Br J Psychiatry 1975a; 9: 11-17. 
Kendell RE. The role of diagnosis in psychiatry. Oxford: Blackwell Scientific Publication; 1975 b.

Kendell RE, Brockington IF, Leff JP. Prognostic implications of six alternative definitions of schizophrenia. Arch Gen Psychiatry 1979; 36: 25-31.

Kendell RE. The choice of diagnostic criteria for biological research. Arch Gen Psychiatry 1982; 39: 13341339.

Kendell RE. Diagnosis and classification of functional psychoses. Br Med Bull 1987, 43: 499-513.

Kendell RE. Clinical validity. Psychol Med 1989; 19: 45-55.

Kendler KS. Towards a philosophical structure for psychiatry. Am J Psychiatry 2005; 162: 433-440.

Kitamura T, Okazaki Y, Fujinawa A, Yoshino M, Kasahara Y. Symptoms of psychoses. A factor-analytic study. $\mathrm{Br}$ J Psychiatry 1995; 166: 236-240.

Klimidis S, Stuart GW, Minas IH, Copolov DL, Singh BS. Positive and negative symptoms in the psychoses. Reanalysis of published SAPS and SANS global ratings. Schizophr Res 1993; 9: 11-18.

Kremen WS, Buka SL, Seldman LJ, Goldsteun JM, Koren D, Tsuang MT. IQ decline during childhood and adult psychotic symptoms in a community sample: A 19year longitudinal study. Am J Psychiatry 1998; 155: 672677.

Leff J, Sartorius N, Jablensky A, Korten A, Ernberg G. The international pilot study of schizophrenia: Five-year follow-up findings. Psychol Med 1992; 22: 131-145.

Leonhard K. Aufteiling der endogenen Psychosen un ihre differenzierte Ätiologie. Stuttgart: Thieme Verlag; 1995.

Lewine RRJ, Fogg L, Meltzer HY. Assessment of negative and positive symptoms in schizophrenia. Schizophr Bull 1983; 9: 368-376.

Liddle PF. The symptoms of chronic schizophrenia. A re-examination of the positive-negative dichotomy. $\mathrm{Br} \mathrm{J}$ Psychiatry 1987a; 151: 145-151.

Liddle PF. Schizophrenic syndromes, cognitive performance and neurological dysfunction. Psychol Med 1987b; 17: 49-57.

Liddle PF, Barnes TRE. Syndromes of chronic schizophrenia. Br J Psychiatry 1990; 157: 558-561.

Liddle PF, Carpenter WT, Crow T. Syndromes of schizophrenia. Br J Psychiatry 1994; 265: 721-727.

Lieberman JA. Signs and symptoms. What can they tell us about the clinical course and pathophysiologic processes of schizophrenia? Arch Gen Psychiatry 1995; 52: 361363.
Löffler W, Häfner H. Dimensionen der schizophrenen Symptomatik. Nervenarzt 1999; 70: 416-429.

Lorr M, Klett CJ, Mcnair DM. Syndromes of psychosis. Oxford: Pergamon Press; 1963.

Lykouras L, Oulis P, Psarros K, Daskalopoulou E, Botsis A, Christodoulou GN et al. Five-factor model of schizophrenic psychopathology: How valid is it? Eur Arch Psychiatry Clin Neurosci 2000; 250: 93-100.

Matsuura M, Adachi N, Oana Y, Okubo Y, Kato M, Nakano T et al. A polydiagnostic and dimensional comparison of epileptic psychoses and schizophrenia spectrum disorders. Schizophr Res 2004; 69: 189-2001.

McGlashan TH, Fenton WS. Classical subtypes for schizophrenia: literature review for DSM-IV. Schizophr Bull 1991; 17: 609-623.

McGorry PD, Singh BS, Connell S, McKenzie D, Van Riel RJ, Copolov DL. Diagnostic concordance in functional psychosis revisited: a study of inter-relationship between alternative concepts of psychotic disorder. Psychol Med 1992; 22: 367-378.

McGorry PD, Bell RC, Dudgeon PL, Jackson HJ. The dimensional structure of first episode psychosis: an exploratory factor analysis. Psychol Med1998; 28: 935947.

McGuffin P, Farmer A, Gottesman II, Murray RM, Reveley AM. Twin condordance for operationally defined schizophrenia. Arch Gen Psychiatry 1984; 41: 541-545.

McGuffin P, Farmer A, Harvey I. A polydiagnostic application of operational criteria in studies of psychotic illness. Arch Gen Psychiatry 1991; 48: 764-770.

McGuffin P, Farmer A. Polydiagnostic approaches to measuring and classifying psychopathology. Am J Med Genet 2001; 105: 39-41.

McIntosh AM, Forrester A, Lawrie SM, Byrne M, Harper A, Kestelman JN et al. A factor model of the functional psychoses and the relationship of factors to clinical variables and brain morphology. Psychol Med 2001; 31: 159171.

Michie PT, Kent A, Stienstra R, Castine R, Johnston J, Dedman $\mathrm{K}$ et al. Phenotypic markers as risk factors in schizophrenia: Neurocognitive functions. Aust N Z J Psychiatry 2000; 34 (Suppl): S74-S85.

Milev P, Ho BC, Arndt S, Andreasen NC. Predictive values of neurocognition and negative symptoms on functional outcome in schizophrenia: A longitudinal first-episode study with 7-year follow-up. A J Psychiatry 2005; 162 : 495-506.

Mishara AL, Goldberg TE. A meta-analysis and critical review of the effects of conventional neuroleptic treatment 
on cognition in schizophrenia: Opening a closed book. Biol Psychiatry 2004; 55: 1013-1022.

Mohamed S, Paulsen JS, O'Leary D, Arndt S, Andreasen N. Generalized cognitive deficits in schizofrenia. Arch Gen Psychiatry 1999; 56 (8):749-754.

Nieuwenstein MR, Aleman A, De Haan EHF. Relationship between symptom dimensions and neurocognitive functioning in schizophrenia: A meta-analysis of WCST and CPT studies. J Psychiatr Res 2001; 35:119-125.

Norman RMG, Malla AK. Duration of untreated psychosis: a critical examination of the concept and its importance. Psychol Med 2001; 31: 381-400.

O'Leary DS, Flaum M, Kesler ML, Flashman LA, Arndt S, Andreasen NC. Cognitive correlates of the negative, disorganized, and psychotic symptom dimensions of schizophrenia. J Neuropsychiatry Clin Neurosci 2000; 12: 4-15.

Olin SCS, Mednick SA, Cannon T, Jacobsen B, Parnas JL, Schulsinger F, Schulsinger H. School teacher ratings predictive of psychiatric outcome 25 years later. Br J Psychiatry 1998; 172: 7-13.

Peralta V, Cuesta MJ, De Leon J. An empirical analysis of latent structures underlying schizophrenic symptoms: a four-syndrome model. Biol Psychiatry 1994; 36: 726-736.

Peralta V, Cuesta MJ. Motor features in psychotic disorders I: Factor structure and clinical correlate. Schizophr Res 2001; 47: 107-116.

Peralta V, Cuesta MJ, Martinez-Larrea A, Serrano JF. Patterns of symptoms in neuroleptic-naïve patients with schizophrenia and related psychotic disorders before and after treatment. Psychiatry Res 2001; 105: 97-105.

Pope HG, Lipinski JF. Diagnosis in schizophrenia and manic-depressive illness. Arch Gen Psychiatry 1978; 35 : 811-828.

Ragland JD. Profiles of neuropsychologic function in schizophrenia. Curr Science 2003; 5: 299-302.

Ratakonda S, Gorman JM, Yale SA, Amador XF. Characterization of psychotic conditions. Arch Gen Psychiatry 1998; 55: 75-81.

Reynolds JR. On the pathology of convulsions with special reference to those of children. Liverpool Med Chir J 1858; 2: 1-14.

Rosenman S, Korten A, Medway J, Evans M. Dimensional versus categorical diagnosis in psychosis. Acta Psychiatr Scand 107: 378-384, 2003.

Rund BRR. A review of longitudinal studies of cognitive function in schizophrenia patients. Schizophr Bull 1998; 24: 425-435.
Salokangas RKR. Structure of schizophrenic symptomatology and its changes over time: Prospective factoranalytical study. Acta Psychiatr Scand 1997; 95: 32-39.

Scharfetter C. The psychopathological background of the AMDP-system. In: Ban TA, Freyhan FA, Pichog P, Pöldinger W, editors. Modern problems of pharmacopsychiatry, vol 20. New York: Kanger; 1983.

Schneider K. Klinische Psychopathologie. Stuttgart: Georg Thieme Verlag; 1950.

Schneider K. Primäre und sekundäre Symptome bei der Schizophrenie. Fortschr Neurol Psychiatr 1957; 25: $487-$ 490.

Schwartz JE, Fennig S, Tanenberg-Karant M, Carlson G, Craig T, Galambos N et al. Congruence of diagnoses 2 years after a first-admission diagnosis of psychosis. Arch Gen Psychiatry 2000; 57: 593-600.

Serretti A, Macciardi F, Smeraldi E. Identification of symptomatologic patterns common to major psychoses: Proposal for a phenotype definition. Am J Med Genet 1996; 67: 393-400.

Serretti A, Rietschel M, Lattuada E, Krauss H, Schulze TG, Müller DJ et al. Major psychoses symptomatology: factor analysis of 2241 psychotic subjects. Eur Arch Psychiatry Clin Neurosci 2001; 251: 193-198.

Serretti A, Olgiati P. Dimensions of major psychoses: a confirmatory analysis of six competing models. Psychiatry Res 2004; 127: 101-109.

Serretti A, Mandelli L, Lattuada E, Smeraldi E. Depressive syndrome in major psychoses: A study on 1351 subjects. Psychiatry Res 2004; 127: 85-99.

Stephens JH, Astrup C, Carpenter WT, Shaffer JW, Goldberg J. A comparison of nine systems to diagnose schizophrenia. Psychiatr Res 1982 ; 6: 127-143.

Stip E. Happy birthday neuroleptics! 50 years later: la folie du doute. Eur Psychiatry 2002; 17: 115-119.

Strauss JS, Carpenter WT, Bartko JJ. The diagnosis and understanding of schizophrenia. Part III: Speculations on the processes that underlie schizophrenic symptoms and signs. Schizophr Bull 1974; 11: 61-69.

Stuart GW, Pantelis C, Klimidis S, Minas IH. The threesyndrome model of schizophrenia: Meta-analysis of an artefact. Schizophr Bull 1999; 39: 233-242.

Van Der Does AJW, Dingemans PM, Linszen DH, Nugter MA, Scholte WF. Symptom dimensions and cognitive and social functioning in recent-onset schizophrenia. Psychol Med 1993a; 23: 745-753.

Van Der Does, A.J.W., Linszen, D.H., Dingemans, P.M., Nugter, M.A., Scholte, W.F. A dimensional and categorical approach to the symptomatology of recent-onset schizophrenia. J Nerv Men 1993b; 181: 744-749. 
Van Der Does AJW, Dingemans PM, Linszen DH, Nugter MA, Scholte WF. Dimensions and subtypes of recent-onset schizophrenia. A longitudinal analysis. J Nerv Ment Dis 1995; 183: 681-687.

Van Der Does AJW, Dingemans PM, Linszen DH, Nugter MA, Scholte WF. Symptoms, cognitive and social functioning in recent-onset schizophrenia: a longitudinal study. Schizophr Res 1996; 19: 61-71.

Van Der Heijden FMMA, Tuinier S, Pepplinkhuizen L, Van Praag HM, Verhoeven WMA. Beyond the mainstream: The heuristic value of the cycloid psychosis. Eur J Psychiatry 2002; 16: 15-26.

Van Der Heijden FMMA, Tuinier S, Kahn RS, Verhoeven WMA. Nonschizophrenic psychotic disorders: The case of cycloid psychoses. Psychopathology 2004; 37: 161-167.

Van Der Heijden FMMA, Tuinier S, Arts NJM, Hoogendoorn M, Kahn RS, Verhoeven WMA. Catatonia: Disappeared or under-diagnosed. Psychopathology 2005; 38: 3-8.

Van Os J, Fahy TA, Jones P, Harvey I, Sham P, Lewis S et al. Psychopathological syndromes in the functional psychoses: associations with course and outcome. Psychol Med 1996; 26: 161-176.

Van Os J, Gilvarry C, Hale R, Van Horn E, Tattan T, White I, Murray R. A comparison of the utility of dimensional and categorical representations of psychosis. Psychol Med 1999; 29: 595-606.

Van Praag HM. About the impossible concept of schizophrenia. Compr Psychiatry 1976; 17: 481-497.

Van Praag HM. The scientific foundation of anti-psychiatry. Acta Psychiatr Scand 1978; 58: 113-141.

Verdoux H, Liraud F, Bergey C, Assens F, Abalan F, Van Os J. Is the association between duration of untreated psychosis and outcome confounded? A two year follow-up study of first-admitted patients. Schizophr Res 2001, 49: 231-241.

Verhoeven WMA, Van Der Heijden FMMA, Wijers FWHM, Tuinier S. Novel antipsychotics: Facts and fictions. Clin Neuropsychiatr J Treatm Evaluation 2005. (in press).
Von Knorring L, Lindström E. Principal components and further possibilities with the PANSS. Acta Psychiatr Scand 1995; 91: 5-10.

Walker E, Lewine RJ. The positive/negative symptom distinction in schizophrenia. Validity an etiological relevance. Schizophr Res 1988; 1: 315-328.

World Health Organization. Report of the international pilot study of schizophenia. Geneva: John Wiley \& Sons, Ltd; 1973.

World Health Organization. Schizophrenia. An international follow-up study. Geneva: John Wiley \& Sons, Ltd; 1979.

Wiersma D, Wanderling J, Dragomericka E, Ganev K, Harrison G, An Der Heiden W, et al. Social disability in schizophrenia: Its development and prediction over 15 years in incidence cohorts in six European centres. Psychol Med 2000; 30: 1155-1167.

Wieselgren IM, Lindström E, Lindström LH. Symptoms at index admission as predictor for 1-5 year outcome in schizophrenia. Acta Psychiatr Scand 1996; 94: 311-319.

Wing JK. A simple and reliable subclassification of chronic schizophrenia. J Ment Sci 1961; 107: 826-875.

Wing JK. Clinical concepts of schizophrenia. In: Wing JK editor. Schizophrenia: towards a new synthesis. London: Academic Press; 1978. p. 1-30.

Yung AR, Philips LJ, McGorry PD, Mcfarlane CA, Francey S, Harrigan S et al. Prediction of psychosis: A step towards indicated prevention of schizophrenia. Br J Psychiatry1998; 172 (Supp1): S14-S20.

Zobel A, Maier W. Endophänotypen: ein neues Konzept zur biologischen Charakerisierung psychischer Störungen. Nervenarzt 2004; 75: 205-214.

Address for correspondence:

Prof.Dr. Willem M.A. Verhoeven, M.D., Ph.D.

Vincent van Gogh Institute for Psychiatry

Stationsweg 46

5803 AC Venray, The Netherlands

Phone: 0031.478527339

Fax: 0031.478527110

e-mail: wverhoeven@vvgi.nl

THE NETHERLANDS 